\title{
MOVING BEYOND THE BOUNDARIES OF ENGINEERING Communication: Teaching Media Savviness to ENGINEERING STUdents
}

\author{
Alan Chong \\ University of Toronto \\ alan.chong@utoronto.ca
}

\begin{abstract}
Engineering communication is most frequently thought of and taught as technical communication for academic and industrial purposes, and considered best taught in deeply integrated and discipline specific contexts. While productive, this focus neglects an increasingly important aspect of the communication many engineers will need to do in their careers - communication with and to the public.

This paper describes an elective course for undergraduate engineers designed to fill this gap through a media literacy approach, developing a theoretical foundation for popular science communication and applying it to various high profile case studies. This approach has been effective in developing a positive learning environment within a small seminar classroom and engaging students on the topic of how their work is communicated to non-expert audiences.
\end{abstract}

Keywords: Science communication, Public understanding of science, Popular science, Engineering communication, Science journalism, Science and engineering engagement, Outreach.

\section{INTRODUCTION}

By the weight of its inclusion amongst the key competencies identified by both accreditation agencies in the United States (ABET) and Canada (CEAB), engineering communication has long been an important part of engineering curricula. Most approaches to teaching engineering communication value an integrated, discipline specific approach, focusing instruction on rhetorical principles within a technical curriculum, on technical topics or as part of the design process. By learning within an engineering context, students develop communication skills and knowledge specific to the content and practices of their disciplines.

Yet such an approach can neglect some of the other important modes of communication engineers (and scientists) may need to engage in over the course of their careers, particularly at the intersections of science and the public. Civil engineers, for example, often are forced to convey their messages around proposals, impending projects, safety failures, etc. to the public through the media. Bioengineers, who work at the intersection of medicine, health, and public policy also frequently engage with the public around the significance of developments in medical technology.

The public communication of science (and engineering) is an important field of understanding for many of our engineers' success, yet it is not taught in many structured ways. Its importance is recognized by the multiple venerable institutions dedicated to its promotion - for example, the American Association for the Advancement of Science, the Royal Society, the Royal Canadian Institute for Science, all of whom award annual prizes for contributions to public engagement.

More recently, initiatives dedicated to the public engagement with science and engineering - such as the University of Toronto's Science and Engineering Engagement (S.E.E.) - have developed with the mandate of bringing together school outreach efforts with broader engagement efforts. At the University of Toronto, this includes a Science Leadership program, which teaches faculty members communication and media strategies for dealing with the public [1].

There remains a gap, however, at the undergraduate level: this paper describes an attempt to fill this gap through an elective course. Essentially, such a course can be taught in two ways. The first is as a "How-to" course, focusing on developing principles and strategies required to communicate to the media. Such a strategy works well in graduate and faculty contexts, since students can apply the techniques learned to their own research. In an undergraduate setting, however, where students do not have specific research projects to hone these techniques, a second method be more effective: learning about popular science communication by analyzing controversial and important cases. The urgency of these cases helps with engagement, and critical analysis of these cases facilitates a media savvy which will then foster the students' development of techniques and strategies for the poplar communication of science. 
This is the approach taken by Science and Engineering the Popular Media, an undergraduate elective course for engineers that begins by establishing a theoretical framework from models of popular science, an understanding of journalistic processes and values, as well as knowledge of popular audiences and applies that to key case studies to elicit techniques and strategies. This paper describes part of the theoretical framework outlined in the opening weeks of the course, several cases applied in this course, focusing on the learning objectives for each case and techniques for developing a media savvy in undergraduate engineering students. It then describes the methods of assessment and, using course evaluation feedback, examines the efficacy of this approach in developing an awareness and understanding of the public communication of science.

\section{SCIENCE COMMUNICATION THEORY}

The course begins by establishing a vocabulary and theoretical framework for science communication studies, opening with a brief grounding in the history of science, focusing particularly on the split between academic and popular science. By looking initially at texts such as Darwin's Origin of the Species, we quickly establish the significant differences between contemporary and historical scientific discourses. Heralded by the birth of the academic research paper, this split also results from the explosion in scientific discovery post industrial revolution (but particularly in the early $20^{\text {th }}$ Century), leading to increasingly specialized communities of practice and the development of specialized scientific discourses distant from popular modes of communication.

Having established the reasons for the bifurcation of scientific discourse into the academic and popular, we examine: first, multiple current stories from the Science section of a major newspaper (often the New York Times) to identify the characteristics of popular science stories; and second, a single case study involving all of the contributing pieces of one contemporary of popular science article, including the research paper, the backgrounder produced by the research lab, the university's press release, and finally, the article itself.

These cases set up an understanding of the journalistic versus scientific values and processes which help to shape how science is portrayed in the popular media, which constitute our first major theoretical frame for understanding popular science. Specifically, we examine how: (1) Topics chosen reflect core journalistic values and processes (health/medicine over physics); (2) how content chosen privileges journalistic values rather than the scientific method (applications/future work over methodology); (3) scientific validity is often overshadowed by journalistic balance; (4) journalistic accuracy (via appeal to authority) substitutes for scientific accuracy. [2]
Our initial forays into science journalism and development of an understanding of journalistic processes sets up a discussion of Models of Popular Scientific Communication, starting with the Deficit Model. In this traditional understanding, scientists are percevied as an authoritative, united source of knowledge, speaking a different language from a public assumed to be lacking in science literacy and any inherent interest in science. The work of communicating between these two parties falls to other agents and institutions - reporters and media organizations - who do the work of translation from academic to popular discourse [3].

This initial model is interrogated throughout the course and, as we examine more case studies, is shown to be flawed in a variety of ways. In particular, we question the idea of translation as a metaphor for the work of science communicators, asking what is "lost in translation" or, alternatively, what is potentially gained as we move to qualitatively different types of information serving different purposes and audiences. We challenge the idea that scientists are a singular, homogenous voice with an authoritative message and, on the other side, the assumptions of low science literacy and low engagement, as well the idea of a singular and consistent "public" unwilling or unable to speak directly to scientists, particularly given new media technologies developed over the past decade. These challenges lead to a deeper understanding of the complex relationship between science and the public that then inform our readings of various case studies.

This more complex understanding of how science is communicated to the public, particularly to multiple audiences, leads to the concept of Framing Science, articulated best by Chris Mooney and Matthews Nisbet in a 2007 editorial in Science. In this editorial, Mooney and Nisbet argue that "Without misrepresenting scientific information on highly contested issues, scientists must learn to actively "frame" information to make it relevant to different audiences." Frames, for Mooney and Nisbet, "organize central ideas, defining a controversy to resonate with core values and assumptions. Frames pare down complex issues by giving some aspects greater emphasis. They allow citizens to rapidly identify why an issue matters, who might be responsible, and what should be done." Poor framing, they argue, is at fault for the ongoing, contentious relationship between evolutionary theory and religion, pointing towards science's (and prominent scientists such as Richard Dawkins and PZ Myers) continuing deployment of scientific modes of argumentation and data in efforts to convince the religious of evolutionary theory. Alongside their belittling of religious beliefs, this mode of argumentation does little than reinforce the scientific establishment's failure to reach these audiences. On the other hand, they point to the framing of the embryonic stem cell debate in terms of America's economic and scientific competitiveness as an 
example of successful communication leading to change [4]. By examining their editorial as well as the response from scientists, many of which warn of a slippery slope from science to ideology, we establish another mode for understanding the challenges involved in science communication that is particularly valuable for contentious public discourses on science [5].

In addition to this theoretical framework, we also examine techniques for communicating science, such as metaphor and narrative. Since popular science communication must often explain foreign concepts to readers, metaphor, which relies on something known to explain something new, is a fundamental strategy. By examining the components of metaphor closely, we can identify how scientific concepts are explained to the public, as well as what is lost or gained in the explanation. The foundation of this understanding of metaphor lies in the concepts of the source and target: the metaphor ascribes implicit or explicit characteristics of source to the target. But it is in the concept of grounds and tension between the source and target where meaning in scientific communication is often made: the grounds are the elements of similarity between the source and target, but it is often in the tension - the various ways in which the target is not like the source - that science communication develops meaning. Take, for example, the following description of atomic structure from Bill Bryson's A Short History of Nearly Everything, which depends heavily on the tensions in his analogy to develop a precise understanding.

The picture that nearly everyone has in mind of an atom is of an electron or two flying around a nucleus, like planets orbiting a sun. ... It is completely wrong, but durable just the same. In fact, ... electrons are not like orbiting planets at all, but more like the blades of a spinning fan, managing to fill every bit of space in their orbits simultaneously (but with the crucial difference that the blades of a fan only seem to be everywhere at once; electrons are) .. the electron doesn't fly around the nucleus like a planet around its sun, but instead takes on the more amorphous aspect of a cloud. The "shell" of an atom isn't some shiny casing, as illustrations sometimes encourage us to suppose, but simply the outermost of these fuzzy electron clouds, [which is] just a zone of statistical probability. Thus, an atom ... would look more like a very fuzzy tennis ball than a hard edged metallic sphere (but not much like either ... ) [6]

Exploring tools such as metaphor helps provide both a conceptual understanding of how science communication operates and gives them tools for doing themselves, which begins to tie theory and critical analysis to practice.

\section{CASE STUDIES IN SCIENCE COMMUNICATION}

This theoretical framework and toolkit for understanding and doing science communication - only a small fragment of which is described above - is applied to a variety of case studies. In actuality, however, these theories, tools, and cases and the theory are developed in concert. The theory helps us develop and understanding of the case, but the reverse is also true. This section describes three representative case studies used in the course: the 2009 L'Aquila verdicts, the representation of the Higgs Boson in popular media, and a 2010 NASA Astrobiology press conference. As well, we describe how issues around climate change communication are engaged through multiple media to explore many of the issues around popular science communication.

\subsection{The L'Aquila Verdicts}

The introductory lecture to the course outlines the case of the L'Aquila verdicts, in which a group of Italian semiologists and public servants were initially found guilty of manslaughter for their failure to adequately communicate the risk of an earthquake in central Italy in 2009. Examining the intricacies and the failures of communication that contributed to the severity of the disaster, the contentious nature of the verdicts themselves, and the scientific community's response to them allows students to understand the importance of science communication to public life. In particular, it demonstrates the link between science and risk communication, as well as how different assumptions about the role of scientists in public safety and policy can shape their interaction with the public. The short press conference held by the Major Risks Commission Meeting at L'Aquila, where none of the scientists and only a bureaucrat spoke - and told reporters that people should just enjoy a nice Montepulciano - also demonstrates the dangers of translation and oversimplification, and the multiple ways in which scientists can be silenced. Furthermore, we discuss the challenges involved in communicating probability and uncertainty in scientific modeling, particularly in fields like seismology in which short term predictions are not possible (versus, say, hurricane forecasting, in which short term predicts for landfall, severity, etc. can be very accurate). In a single case that opens the course, we demonstrate how high the stakes can be in science communication, and how failures can lead to challenges for both the public and for science. [7-8]

\subsection{The Higgs' Boson}

The communication around the Higgs' Boson represents an anomaly for popular science, in that it is the result of massive outreach effort on the part of scientists, science communicators, and regular journalists. While we begin by looking at sensationalistic science journalism that focused on the complexity of the physics and the end of the world scenarios popularized around the Large 
Hadron Collider's (LHC) launch, we quickly move to collaborative projects between scientists and science communicators to explain the science and its significance, a goal necessitated by the huge economic investment in the project. This wide range of popular materials developed to justify and explain the Large Hadron Collider to the public begins our exploration of the role of multiple media in science communication, and what is possible with collaboration: among other things, we look at a Quirks and Quarks podcast from the launch of the LHC [9], the LHC rap [10] produced at CERN, and a $\mathrm{Ph} . \mathrm{D}$. comics based video which uses animation to support an impromptu explainer [11]. These multimedia examples allow us to examine the use of metaphor, narrative, and other techniques at play in explain challenging scientific concepts, and also challenge the Deficit Model assumptions around a single, homogenous audience, and a science community disinterested in engaging with the public.

\subsection{The NASA Astrobiology Presser}

In contrast to the communication about the LHC, NASA's 2010 Astrobiology Press Conference demonstrated many of the dangers of modern publis relations techniques in communicating about science. The presser was heralded as making an announcement that would "impact the search for extraterrestrial life," [12] with a three-day embargo (until just before the scheduled conference). Unsurprisingly, the embargo provided fertile ground for speculation, leading to high expectations about the discovery of extraterrestrial life. When the actual conference [13], which included several scientists in addition to the primary investigator (PI), announced "only" the discovery of an arsenic (instead of phophrous) based bacteria, GFAJ-1, the public was understandably disappointed, not only in the discovery, but in the mode of communication The delivery of the information by the PI, Felisa Wolfe-Simon, was heavily critiqued for multiple affectations, as was the overproduced promotional, multimedia video developed to support her speech. As well, the dynamic between the PI, the other scientists, and the audience created multiple awkward moments within the announcement, creating personalities that came off as bracing rather than welcoming or accommodating. Further, the publicity of the news created an increased scrutiny that led to multiple, significant challenges to the paper's results in the public realm - via social media, alternative news outlets such as Slate.com, and scientist blogs. This case allowed us to explore the impact of various aspects of the modern science communication process, including the embargo, the failures of peer review, as well as of the impact of public debate on academic scientific communication.

\subsection{Climate Change Communication}

Our sustained module on climate change communication consists of multiple historic as well as contemporary newspaper articles, research into shifting public and partisan opinion on climate change, as well as landmark movies such as An Inconvenient Truth and, more recently, Before the Flood. This large and varied set of texts enables discussion of nearly all of the theoretical frames and techniques establish early on in the course. Given climate change science's deeply partisan reception, particularly in the United States, it affords us an excellent opportunity to discuss the concept of framing, as well as to explore the intersections between science, politics, ethics, and economics, particularly as scientists explore different frames for explaining climate change in ways that motivate social action. By doing so, climate change research also challenges the degree to which science can be non-ideological or divest itself from political action. Finally, it also gives us an opportunity to explore research into science communication, since climate change is one of the most widely studied topics in that field.

\section{ASSESSMENT}

Assessment focuses on students' ability to apply the theoretical frameworks to critical analyses of various texts, or their ability to use various techniques in developing pieces of popular science communication. In addition to a final exam, students must complete two projects, both with an oral and written component.

In their first assignment, students choose a recent research development, tracking its path and critically analyzing its portrayal in the popular media. Students present their ideas orally in a short presentation first, and then take the feedback provided in class and in the assessment to complete their critical essay. Alternatively, students can also choose to write a popular media article for a specific media outlet - this year, Research2Reality, a University of Toronto based Canadian focused popular science outlet - accompanied by a justification of their approach and technique. This option was scaffolded by a visit from an R2R writer, who spoke to the class about her position as science communicator, as well as the site's guidance on audience, purpose, and structure.

In their second assignment, students choose a larger topic, rather than a single article, creating a case study for the class. They are encouraged to perform research - in both in popular and academic sources - to develop a longer (approx. $30 \mathrm{~min}$ ) seminar with lecture, activity, and Q\&A to teach the case to their peers, which they then turn into a longer paper. In the case of the second assignment, the creative alternative in this case is a podcast on a contemporary science issue, again accompanied by a justification for audience, approach, and techniques. Students are encouraged to develop an 
area of their own interest, and have engaged topics such as: the impact of nature documentaries on public understanding and engagement with environmental issues, Climategate reporting and its influence on the Copenhagen Summit, Mythbusters and the Scientific Method, Youtube videos as Science Communication genre, among others.

\section{EVALUATIONS}

Evaluations for the course have been quite positive. Quantitative metrics suggest that both the media literacy approach and the structure of classes contribute to a productive learning environment for students. Tables 1-4 shows the responses, on a five point Likert scale, to several key questions in the course evaluation framework over the last four years (2014-2017).

Table 1: Overall, the quality of my learning experience in this course was ... (1: Poor, 2: Fair, 3: Good, 4: Very Good, 5: Excellent)

\begin{tabular}{|l|l|l|l|}
\hline 2014 & 2015 & 2016 & 2017 \\
\hline 4.6 & 4.2 & 4.6 & 4.3 \\
\hline
\end{tabular}

Table 2: The instructor created an atmosphere that was conducive to my learning. (1: Not at all, 2: Somewhat, 3: Moderately, 4: Mostly, 5: A Great Deal)

\begin{tabular}{|l|l|l|l|}
\hline 2014 & 2015 & 2016 & 2017 \\
\hline 4.9 & 4.8 & 4.9 & 4.8 \\
\hline
\end{tabular}

Table 3: I found the course intellectually stimulating. ( 1 : Not at all, 2: Somewhat, 3: Moderately, 4: Mostly, 5: A Great Deal)

\begin{tabular}{|l|l|l|l|}
\hline 2014 & 2015 & 2016 & 2017 \\
\hline 4.3 & 4.4 & 4.3 & 4.6 \\
\hline
\end{tabular}

Table 4: The course expanded my understanding of the ethical and environmental issues concerning Engineering in society. (1: Not at all, 2: Somewhat, 3: Moderately, 4: Mostly, 5: A Great Deal)

\begin{tabular}{|l|l|l|l|}
\hline 2014 & 2015 & 2016 & 2017 \\
\hline 4.3 & 4.4 & 4.3 & 4.8 \\
\hline
\end{tabular}

Of greater interest, however, are the qualitative comments, which reveal both how the structure of the course and the approach helped to create a positive learning environment for the students. Speaking about the small, seminar based nature of the course, one student commented:

I would look at issues through one dimension but collaborating with the classmates, hearing their vastly different opinions given their backgrounds and experiences, along with the questions and issues brought up through the course material made it a very enjoyable and enlightening experience.

Even in their mandatory Arts and Science electives, students did not have many small class experiences, and the seminar nature, according to another student, "Gave [her] the opportunity of being able to speak up in front of peers." Other student comments reinforced the importance of the class structure: "Each class had a lecture component, a discussion component and an activity - this was extremely helpful to fully understanding the material and making it appealing."

But the bulk of the comments addressed the general importance and significance of the topic to their chosen fields of study. One student found the media literacy approach to be fundamental to her engagement: "The method of delivering the material is very interesting (media literacy) and provides insight on the importance of the subject of science communication. I really feel that I now will change the way I try to communicate science in the future." Another, comparing their experience in this course to other electives, found it easier to connect with the material and to connect it to their own work:

When I took humanities and social science courses, it was very interesting but I found it hard to figure out how to relate those courses to my engineering experience. Due to the complex nature of scientific material this course helped develop skills for a particular purpose ... [those] that engineers in the real world would need. It is a great stepping stone for anyone who is interested in communicating science to a wide range of audiences. I'm always frustrated because I can't discuss my course material with my art-sci friends, but now I had a way of portraying what I study to them in an interesting way.

\subsection{Conclusion}

Communicating - clearly, purposefully, and accurately - to the public is a neglected yet important skill set for successful engineers, one that needs to be started in their undergraduate careers. This course provides an approach - via media literacy and critical analysis - that enables both an understanding of and ability to do that communication.

\section{References}

[1] University of Toronto. Science and Engineering Engagement. Available from http://scienceengagement.utoronto.ca/

[2] S. Dunwoody, "Science journalism." Handbook of Public Communication of Science and Technology. Eds. M. Bucchi and B. Trench. New York: Routledge, 2008. pp. 15-26.

[3] M. Bucchi, "Of deficits, deviations and dialogues: theories of public communication of science." Handbook of Public 
Communication of Science and Technology. Eds. M. Bucchi and B. Trench, New York: Routledge, 2008, pp. 57-76.

[4] M. Nisbet, and C. Mooney. "Framing science," Science, vol. 316, p. 56, 6 April, 2007.

[5] Letters, Science, vol. 317, pp. 1168-70, 7 August, 2007.

[6] B. Bryson, A Short History of Nearly Everything, Toronto: Anchor Canada, 2004.

[7] S. Hall, “At fault?” Nature, vol. 477, pp. 264-269, 15 Sept 2011.

[8] E. Cartlidge, “Aftershocks in the courtroom.” Science, vol. 338, pp. 184-189, 2 October 2012.

[9] CBC, Quirks and Quarks. Sept 2008. Available from http://www.cbc.ca/radio/quirks/pastepisodes

[10] CERN. Large Hadron Collider Rap. Available from http://vimeo.com/1431471

[11] Ph.D. Comics, The Higgs Boson Explained. Available from http://vimeo.com/41038445

[12] D. Brown, (2010, Nov 29). "NASA Sets News Conference on Astrobiology Discovery; Science Journal Has Embargoed Details Until 2 p.m. EST On Dec. 2," Available from http://www.nasa.gov/home/hqnews/2010/nov/HQ M10167 Astrobiology.html

[13] NASA. (2010). "News Conference on Astrobiology Findings." [Online] Available from https://www.youtube.com/watch?v=WVuhBt03z8g 